\title{
Special Issue on the 2nd International Conference Devices for Integrated Circuits (DevIC-2017)
}

\author{
Jyotsna Kumar Mandal ${ }^{1} \cdot$ Angsuman Sarkar $^{2}$
}

Published online: 15 April 2019

(C) Springer-Verlag GmbH Germany, part of Springer Nature 2019

This is a Special Issue out of 2 nd International Conference on "Devices for Integrated Circuits(Dev IC-2017) published in Microsystem Technology of Springer Nature. This special issue is composed of 15 extended version of peer reviewed papers presented at the International Conference on Devices for Integrated Circuits (DevIC 2017) held during March 23-24, 2017, at BCKV Lake Hall, Kalyani, West Bengal, India.

This Special Issue will provide a focal point for reporting the advancements in order to serve as an educational information resource for the device and design-oriented communities from academia to industry. The Special Issue will be productive and will serve to broaden the perspective for the researchers, scientists, and students in order to unveil new horizons of knowledge in the areas related to the semiconductor devices, Integrated Circuits and microsystems.

The guest editors carefully selected the most interesting works and asked the authors to submit an extended version for publication in this Special Issue. Manuscripts submitted to this Special Issue were rigorously reviewed by experts and researchers form university, industry and development centres. Extended version (at least 50\% as new content and contribution with respect to its conference version) of papers have been refereed, along the usual refereeing process in force at Microsystem Technologies. The acceptance of this special issue was strictly based on the reviewers' recommendations, mandatory revisions, and final examinations conducted and supervised by the guest editors. We would like to thank the authors for their work in submitting and revising their manuscripts.

We express our deepest gratitude to our reviewers for their efforts and dedications. This issue would not have been possible without their expert advice.

The supporting and patient work from of the Editorial Office of "Microsystem Technologies" is also deeply appreciated. Moreover, special thanks are given to the Editor-in-Chief, Prof. Bernd Michel, for his kind support for publication of this issue.

We hope that this Special Issue will be helpful for the reader, researchers and the community.

Guest editors

Dr. Jyotsna Kumar Mandal, University of Kalyani, Kalyani, West Bengal, India.

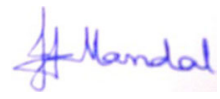

Dr. Angsuman Sarkar, Kalyani Government Engineering College, Kalyani, West Bengal, India.

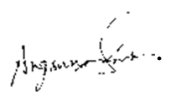

Publisher's Note Springer Nature remains neutral with regard to jurisdictional claims in published maps and institutional affiliations.
Jyotsna Kumar Mandal

jkm.cse@gmail.com

University of Kalyani, Kalyani, West Bengal, India

2 Kalyani Government Engineering College, Kalyani, West Bengal, India 